\title{
O retrato da marca: um estilo artístico adaptado à linguagem dos artefatos industrializados
}

Débora Veríssimo Costa, mestre em comunicação social pela UFMG E-mail: deboracosta72@gmail.com

\begin{abstract}
Resumo
Neste artigo buscamos estabelecer uma possível perpetuação iconográfica no que diz respeito ao uso da linguagem do retrato como um conteúdo em permanente reformulações e retribuições. Em um dado momento histórico, o retrato da cabeça humana fora o símbolo do "duplo", a permanência da alma enquanto imagem. Na contemporaneidade, curiosamente implicado junto a artefatos industrializados, este mesmo símbolo parece persistir como um atestado de resistência/existência humana: cabeças humanas continuam a estampar superfícies como um "símbolo abreviador" constantemente revisitado. Nos voltaremos para uma breve análise das superfícies plásticas de determinadas marcas na tentativa de nos aproximarmos de uma provável iconografia típica a estes símbolos industriais.
\end{abstract}

Palavras-chave: retrato; cabeça humana; marca; artefatos industriais

Introdução

Um símbolo é portanto um sinal abreviador. Podemos o imbuir de espiritualidade e the dar uma alma; podemos, ao contrário, o abater sobre a sua função como forma simplificadora (Rancière, 2003: 116). ${ }^{1}$

Este conceito descrito por Rancière (2003) parece nos apontar uma perspectiva interessante para refletirmos sobre o uso da figura humana, em especial da cabeça humana, como um possível símbolo abreviador de grande valia ao repertório

\footnotetext{
${ }^{1}$ Un symbole est d'abord un signe abréviateur. On peut le charger de spiritualité et lui donner une âme ; on peut, au contraire, le rabattre sur sa fonction de forme simplificatrice (Rancière, 2003: 116).
} 
visual humano, desde a antiguidade. Neste artigo, buscamos estabelecer uma possível perpetuação iconográfica no que diz respeito ao uso da linguagem do retrato como um conteúdo em permanente reformulações e retribuições. Em um dado momento histórico, o retrato da cabeça humana fora o símbolo do "duplo", a permanência da alma enquanto imagem. $\mathrm{Na}$ contemporaneidade, curiosamente implicado junto a artefatos industrializados, este mesmo símbolo parece persistir como um atestado de resistência/existência humana: cabeças humanas continuam a estampar superfícies como um símbolo abreviador constantemente revisitado, mesmo quando implicados junto a marcas comerciais.

Nos voltaremos para uma breve análise das superfícies plásticas de determinadas marcas na tentativa de nos aproximarmos de uma provável iconografia típica a estes símbolos industriais. Intimamente apontados para mercadorias diversas, desde palitos de dentes, a farináceos ou até mesmo ao látex, estes retratos comerciais parecem nos apontar um interessante símbolo abreviador que prospera junto aos artefatos contemporâneos.

\section{O encanto pela cabeça: a profanação da cabeça humana?}

Retomando a fala de Calderón (1971) ao especificar o retrato como uma ilustração artística em que o principal tema é a figura humana, demonstrando uma grande variedade de estilos de representação do modelo - em corpo inteiro, sentado, de perfil, etc. - destacamos aqui, o retrato da cabeça isolada como uma temática não apenas recorrente junto à história da humanidade como também, um indicador que nos aproxima das crenças e anseios humanos.

O "Encanto pela cabeça humana" se assim podemos especificar este fenômeno, nos retoma épocas que datam desde a alta antiguidade. Há mais de quatro mil anos atrás, como parte da cultura egípcia, por exemplo, a produção de máscaras mortuárias nos revelam a intensa elaboração de 
efígies humanas relacionadas, como define Aymar (1967), à crença do duplo. À cada pessoa acreditava-se na existência de um Ka, uma espécie de alma que resistiria após a morte. É de importância destacarmos que, a partir do século I a.C., a representação da cabeça humana nestas máscaras mortuárias, tenderia a tornar-se perpendicular em relação ao restante do corpo, como podemos observar na figura 1 :

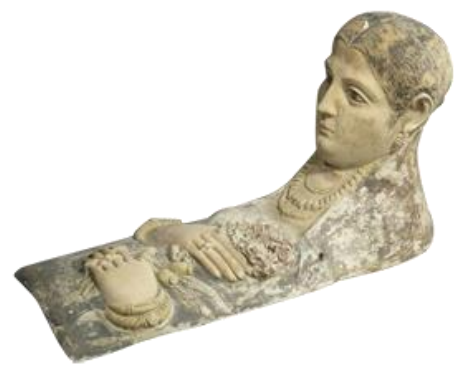

Fig. 1: Máscara mortuária de mulher - final do século III d.C. Fonte: Adaptado de Louvre. ${ }^{2}$

Esse estilo de representação deve-se à interferência da cultura escultórica greco-romana como uma corrente estilística de grande repercussão no mundo inteiro a partir do século VIII a.C. ${ }^{3}$ Bustos e hermas de personalidades oficiais, bem como da elite intelectual greco-romana, nos apontam a insistência na representação da cabeça humana como uma prática habitual entre diferentes culturas.

Símbolo sagrado presente na cultura católica desde a Idade Média, o Véu de Verônica nos alega a impressão fiel da cabeça de Jesus Cristo sobre um véu. Do grego verum Eikôn, ou seja, verdadeiro ícone, esta relíquia católica nos traduz uma espécie de profanação da própria imagem de uma entidade sagrada. Agamben (2007) nos retoma que profanar significa

\footnotetext{
2 Disponível em <http://www.louvre.fr/> acesso em set. 2014.

${ }^{3}$ Para uma leitura mais aprofundada consultar a obra A escultura grega (Beccati, 1965).
} 
restituir ao uso comum o que havia sido separado na esfera do sagrado, nesse sentido, será portanto a imagem da cabeça humana que nos traduzirá esta espécie de sacrifício contido neste movimento entre o sagrado e o profano. É interessante destacarmos que a valorização deste ícone enquanto iconografia, possibilitou a sua perpetuação dentro de uma variável visual:

(a)

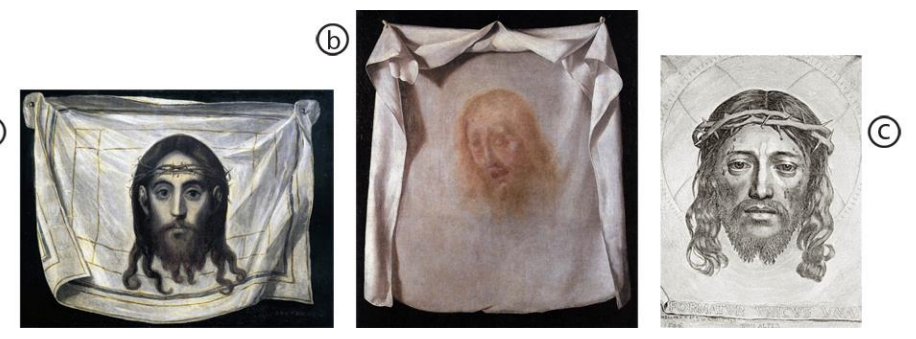

Fig. 2: O Véu de verônica como iconografia: a) EL GRECCO 1580/82, b) FRANCISCO DE SURBARÁN - 1658/61, c) CLAUDE MELLAN - 1659. Fonte: Adaptado de WGA. ${ }^{4}$

Assim como destacamos na figura 2, a cabeça isolada é posicionada no centro do véu, em que os contornos dispostos pelo cabelo e barba do modelo, prestariam as diretrizes irredutíveis à esta iconografia.

É possível analisarmos este movimento de profanação como um sintoma do que viria a ser estabelecido, principalmente a partir do Renascimento, como uma abertura à representação da figura humana enquanto a sua individualidade e "humanidade". Assim como Agamben (2007) retoma, um dos grandes fascínios dentre os filósofos medievais considerava o espelho como um lugar em que descobrimos que temos uma imagem e, ao mesmo tempo, que ela pode ser separada de nós, nos apontando que a nossa "espécie" ou imago não nos pertence. A efervescente produção de retratos a partir do século XV nos aproxima de uma possível resposta a esta "filosofia do espelho", em que além da evolução da técnica e

${ }^{4}$ Disponível em <http://www.wga.hu/> acesso em set. 2014. 
do desdobramento de estilos diversos, os retratistas renascentistas nos apontam para um crescente interesse voltado para a representação da figura humana, ou seja, se a nossa imagem não nos pertence, porque não a capturarmos através do retrato? Não por acaso, será a partir deste período em que se estabelecerá um padrão de perspectivas, utilizado até hoje, para a representação da cabeça humana (figura 3):

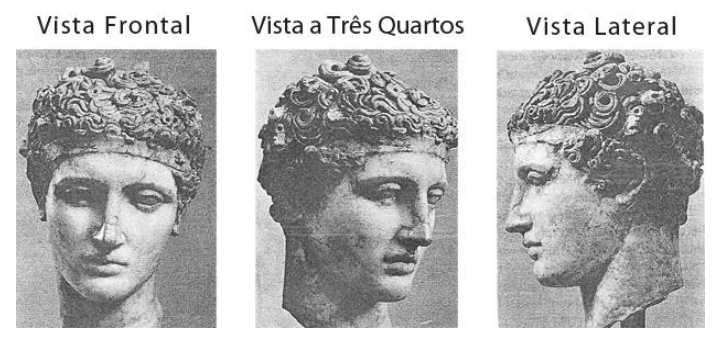

Fig. 3: As três perspectivas da cabeça humana. Fonte: Adaptado de Hogarth, 1965.

A fisionomia esboçada através de cada um destes planos será diretamente associada à natureza dos indivíduos. Seriam os vícios e complexos inscritos no rosto:

as linhas que separam, as maças dos lábios, as asas do nariz, e as órbitas dos olhos, são evidentes quando os homens são alegres e riem com frequência; os que pouco as têm marcadas são homens dedicados à meditação. (Da Vinci, 1954: 118, tradução nossa) ${ }^{5}$

Dois séculos mais tarde, como nos retoma Courtine e Vigarello (2008), será de grande utilidade aos "craniólogos" a dedução das "leis fisionômicas" através da análise de crânios humanos. $O$ intuito seria $o$ de diagnosticar a periculosidade dos condenados.

5 "las líneas que separan las mejillas de los labios de la boca, y las aletas de la nariz, y las órbitas de los ojos, son evidentes cuando los hombres son alegres y ríen con frecuencia; y los que poco las tienen marcadas son hombres dedicados a la meditación". 
A partir destes fatores, podemos começar a desconfiar até mesmo da forma que diversos artistas intitularam, e intitulam até hoje, algumas de suas obras (figura 4):

(a)

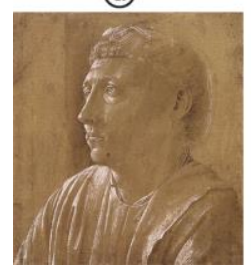

(b)

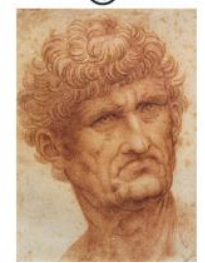

(C)

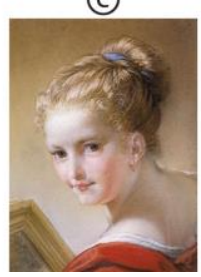

(d)

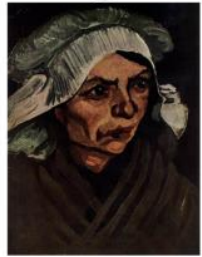

(e)

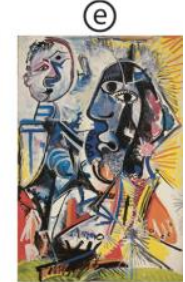

Figura 4: Cabeças: a) Cabeça de clérigo (ANGELO FRA) - 1448, b) Cabeça de homem (LEONARDO DA VINCI) - 1503/05, c) Cabeça de uma mulher jovem (BENEDETO LUTTI) - 1717, d) Cabeça de uma mulher camponesa com um chapéu branco - (VINCENT VAN GOGH) - 1885, e) Cabeças grandes (PABLO PICASSO) - 1969. Fonte: Adaptado de WGA ${ }^{6}$

O simples fato de diversas obras serem intituladas a partir da expressão "cabeça" nos aponta que esta escolha não ocorre ao acaso. Por mais que outras definições como "busto" e "retrato", por exemplo, possam compartilhar destes estilos de representação da figura humana, a eleição da cabeça como uma instância definidora do que seria "ser humano", nos remete não apenas ao antropocentrismo, ao século das luzes, ao ser racional, ou ao próprio crânio, como nos remete também à natureza, aos amores e às inquietações fisionômicas, alojadas, necessariamente, nesta cabeça humana.

Um bom exemplo histórico para refletirmos sobre esta "duplicidade" entre o encanto pela representação da cabeça, e todas as paixões humanas possíveis de serem projetadas na fisionomia, é a guilhotina. Bem antes do século das luzes, como nos aponta Arasse (1989), a utilização da guilhotina decorria de um privilégio aristocrático extraordinário, permitindo à vítima evitar o contato com as mãos do carrasco, enquanto

\footnotetext{
${ }^{6}$ Disponível em <http://www.wga.hu/> acesso em set. 2014.
} 
garantia ao mesmo uma inegável eficácia mecânica. Mais associada à revolução Francesa, como nos assinala Arasse (1989), no ano de 1792 o aperfeiçoamento e a popularização da guilhotina como um método de "execução eficiente" revelaria um estilo de gravura revolucionária que reforçará a cabeça enquanto ícone. O "retrato do guilhotinado" atestaria a fisionomia do traidor no momento da sua decapitação.

Nesse sentido, encontraremos nas origens da guilhotina um processo muito mais voltado para o sagrado, em que a extinção da cabeça do seu corpo significaria o símbolo deste sacrifício, sendo que, a partir da Revolução Francesa, a profusão do retrato do guilhotinado nos remete a um movimento que reafirma a esfera do profano, no sentido de algo sujeitado ao "não humano", e por isso mesmo, representado sobre a forma de uma cabeça isolada brutalmente do seu corpo (figura 5):

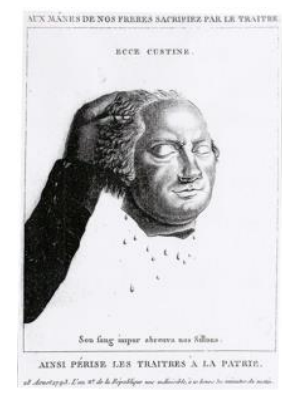

Fig. 5: O retrato de Custine Guilhotinado - 1793. Fonte: Arasse, 1989.

Cabe ressaltarmos também que a mão do carrasco erguendo a cabeça guilhotinada nos conduz àquilo que Agamben (2007) descreve como um "contagio profano", ou seja, um tocar que desencanta e devolve ao uso aquilo que o sagrado havia separado e petrificado.

Ao observarmos os fenômenos contemporâneos que nos atraem nesta direção, encontraremos no âmbito dos artefatos industrializados algumas evidências que corroboram com a manutenção da cabeça enquanto uma instância reguladora na representação da figura humana. A seguir, propomos uma 
breve incursão no que diz respeito ao estilo plástico de algumas marcas que se utilizam de uma iconografia típica a determinados produtos industrializados. A representação da cabeça através do que podemos chamar "retrato da marca" nos auxilia a confirma-la enquanto um "símbolo abreviador" característico da contemporaneidade.

\section{0 retrato da marca: entre personalidades e cabeças anônimas}

Uma curiosa relação com a cultura greco-romana a partir do século III a.C. nos auxiliará a alcançar uma possível explicação para o uso do retrato, enfatizando a cabeça humana, como uma estratégia comercial de grande eficiência propagandística. Quando originada na Lídia (atual Turquia) do século VII a.C., a moeda ocidental tal como a conhecemos atualmente - disco de metal com impressões nas duas faces - teve como uma de suas evoluções mais marcantes, como descreve Costilhes (1985), a inserção de uma inscrição colocada por uma autoridade conhecida, que inspirava confiança e que garantia o "peso", ou seja, o valor da moeda. Utilizadas como um meio de comunicação à época, as moedas greco-romanas apresentavam no anverso o busto ou a cabeça de um monarca, e no reverso as conquistas asseguradas pelo seu império:
A efígie do imperador, gravada com grande realismo no anverso de cada moeda, era levada até os limites do império e além aos outros países com quem comerciavam, transmitindo ainda, através das figuras e legendas gravadas no reverso, as realizações e vitórias do mesmo imperador (Costilhes, 1985: 47).

Não muito distante desta perspectiva, os retratos que compõem algumas marcas comerciais da contemporaneidade, continuam a se valer deste "peso" assegurado por personalidades proeminentes. Como não se perguntar sobre a origem de alguns destes "retratos marcarios"? A quem condiz a efígie que estampa a marca KFC (Kentucky Fried Chicken), por exemplo? De origem norte americana, esta indústria voltada 
para a produção de frango frito traz como chancela à sua superfície plástica marcária, a efígie do seu criador:
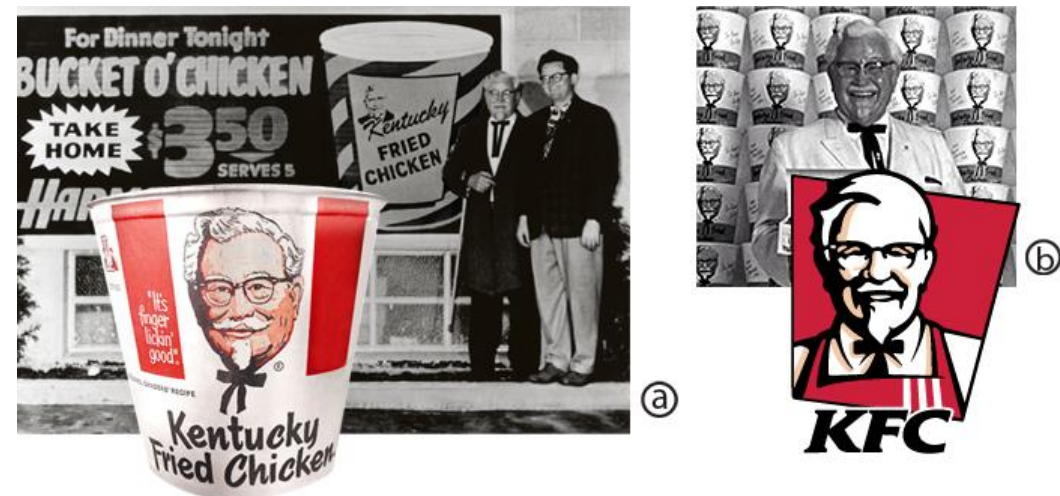

Figura 6: O retrato da marca KFC: a) Coronel Sanders e seu sócio Pete Harman promovendo o novo "Bucket O' Chicken" - 1957, b) Coronel Sanders posa em frente aos famosos baldes KFC - década de 50; marca revitalizada - 2014. Fonte: Adaptado de $\mathrm{KFC}^{7}$; HI-LOW 8

Estampando os famosos baldes desta empresa, Coronel Harland Sanders terá o seu retrato tornado público, feito uma marca registrada. É interessante observarmos que originalmente o retrato de Sanders assume a representação da sua cabeça isolada, assim como observamos no balde exposto na figura 6, sendo que atualmente, a ênfase é dada em função do busto de Sanders. A pequena gravata assinalada desde a origem desta marca parece nos apontar um curioso adereço indispensável ao reconhecimento da celebridade retratada.

Em outros casos, encontraremos o retrato marcário do fundador da empresa utilizado muito mais em função do seu nome incorporado à marca. Presente no mercado brasileiro desde 1954, os pescados Gomes da Costa, nos trazem o nome do fundador desta empresa utilizado feito um "brasão de família":

7 Disponível em <http://www.kfc.com> acesso em set. 2014.

${ }^{8}$ Disponível em <http://www.hi-and-low.typepad.com> acesso em set. 2014. 


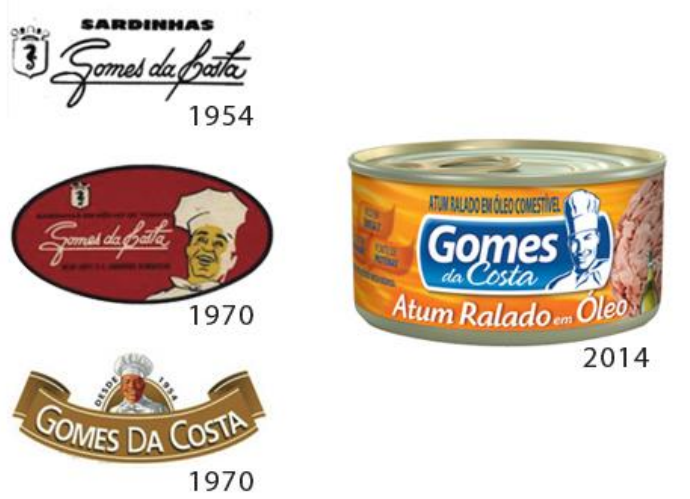

Figura 7: Algumas etapas da evolução da marca "Gomes da Costa". Fonte: Adaptado de Gomes da Costa. ${ }^{9}$

O pequeno escudo que orna a primeira marca "Gomes da Costa", de 1954, nos remete ao que Costa (2008) descreve como um dos processos definidores na evolução das marcas junto à humanidade: a arte heráldica ${ }^{10}$. A importância conferida ao poderio dos reinos durante a Idade Média impulsionará o desenvolvimento de linguagens visuais - formato dos escudos, bandeiras, esmaltarias, etc. - que recaem até hoje na estética das marcas comerciais, como é o caso da primeira marca da Gomes da Costa, assinalada na figura 7. No entanto, observamos que a partir de 1970 o símbolo do escudo cederá espaço a um retrato em busto, nos proporcionando o acesso a uma possível imagem de Gomes da Costa. Simbolizado por um chef, este retrato nos parece uma idealização de um personagem que não necessariamente condiz com a real imagem do fundador desta empresa.

Em diálogo, podemos citar a marca americana Uncle Ben's, voltada para a produção e refino de arroz. No que diz respeito ao nome adotado por esta marca e a personificação desta

\footnotetext{
9 Disponível em <http://www.gomesdacosta.com.br> acesso em set. 2014.

${ }^{10}$ Do latim heraldus: mensageiro. A heráldica também é conhecida como a "arte da guerra".
} 
através de um retrato, encontraremos duas origens diferentes. Uncle Ben foi um fazendeiro afrodescendente que no início da década de 90 ganha destaque enquanto a qualidade dos grãos que produzia. No entanto, o retrato que traduz a sua personificação na marca diz respeito ao famoso chef e garçom californiano, Franck Brown:

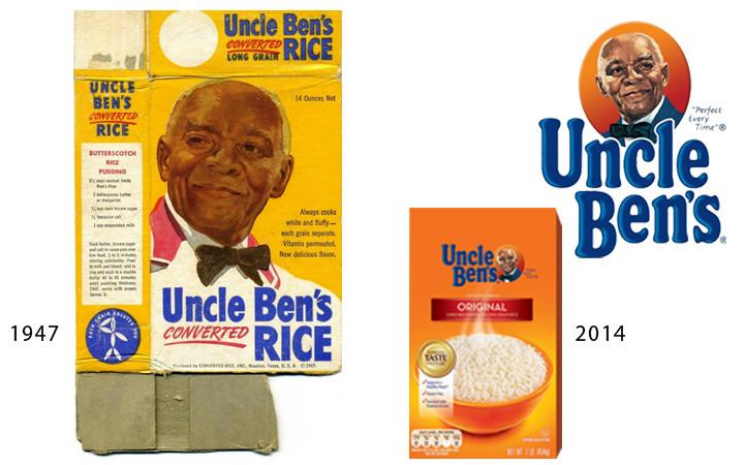

Figura 8: Embalagens e marca da Uncle Ben's. Fonte: Adaptado de Uncle Ben's. ${ }^{11}$

Será portanto através da combinação destas duas variantes que encontraremos um vínculo de notoriedade que estes dois personagens conferem à marca Uncle Ben's. Como podemos observar na figura 8, o retrato em busto utilizado desde 1947, apesar de ter sido refletido para a esquerda, mantem a típica pose do autorretrato: "a cabeça posicionada de $3 / 4$, nem sempre em harmonia com a posição do busto, e os olhos voltados para o espectador" (Masciotta, 1955: 5).

Um caso interesse para analisarmos a veracidade entre 0 retrato da marca e o seu nome é o da empresa espanhola Carmencita, voltada par a produção de especiarias desde 1920:

\footnotetext{
11 Disponível em <http://www.unclebens.com/About-us > acesso em set. 2014.
} 


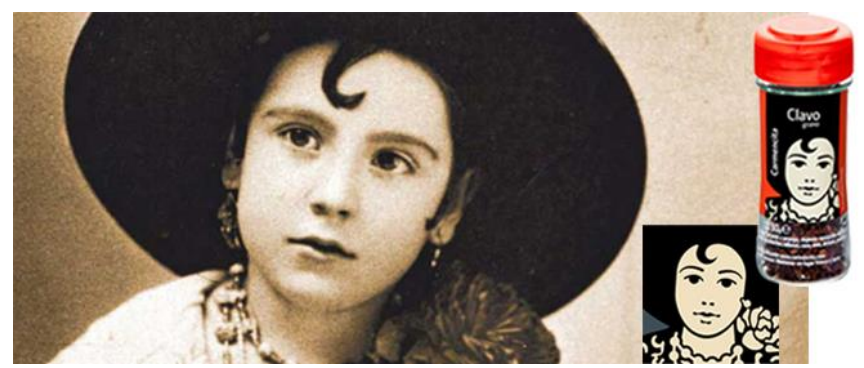

Fig. 9: A veracidade do retrato da marca através da fotografia. Fonte: Adaptado de Carmencita. ${ }^{12}$

Inspirada em um retrato fotográfico da filha do fundador da empresa, Jésus Navarro Jover, podemos observar na figura 9 a atenção conferida aos elementos principais que identificariam a Carmencita da fotografia à da marca: chapéu, cacho, olhos, boca, flor, colar e chale. Nesse sentido, o retrato da marca busca uma fidelidade quase extrema em relação à foto, ou seja, percebe-se a eleição de uma imagem fotográfica ideal para ser readaptada no formato de uma ilustração marcária.

Outro exemplo curioso, também relacionado à readaptação de uma fotografia ao retrato da marca, pode ser analisado através da marca brasileira Gina. Voltada para a produção de artefatos de madeira em geral, a afamada caixa de palitos de dentes desta empresa não teria tanto sucesso, se assim podemos afirmar, se não fosse o retrato e o nome conferidos a esta marca. "Dona Gina", mãe dos fundadores da empresa nos justifica o nome atribuído à marca, fato que não corresponde com o retrato utilizado nesta:

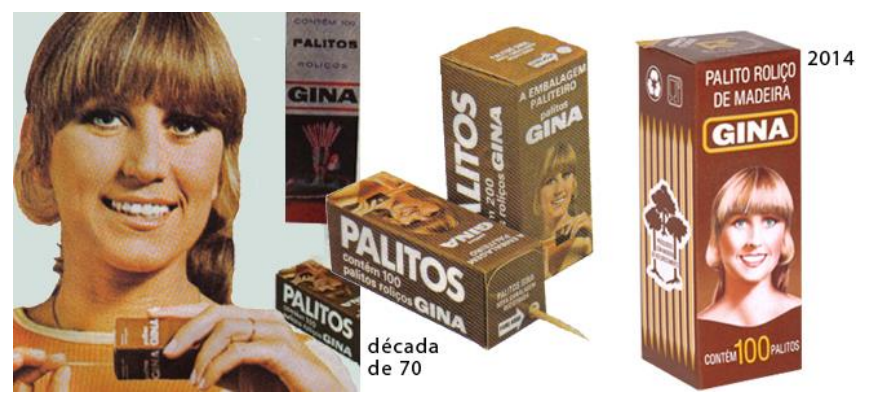

12 Disponível em <http://www.carmencita.com> acesso em set. 2014. 
Fig. 10: A adaptação do retrato fotográfico ao retrato marcario contemporâneo. Fonte: Adaptado de Design Innova; Gina. ${ }^{13}$

A partir de 1975, o retrato fotográfico da modelo Zofia Burk será inserido na composição visual da marca Gina. Nos apontando mais uma vez um caso de personificação da marca, no retrato fotográfico da década de 70 encontramos a personagem manuseando o próprio produto, sendo que a marca adotada atualmente nos mostra a simplificação do retrato no formato do busto, sem a exposição das mãos da modelo. É interessante observarmos neste caso, o uso da fotografia incialmente aplicada de forma direta na caixa de palitos, e a releitura deste retrato fotográfico aos padrões plásticos das marcas contemporâneas, em que a simplificação das linhas e a adoção de cores chapadas, vêm a adaptar a fotografia à linguagem da ilustração (figura 10).

A simplificação das marcas, ou, como define Costa (2008), a perda do "excesso de realismo" a partir do século XIX seria uma linguagem típica do período pós-industrial. Interessanos observar a simplificação, e portanto, a adequação da linguagem do retrato em determinadas marcas do século $X X$ e $\mathrm{XI}$ :

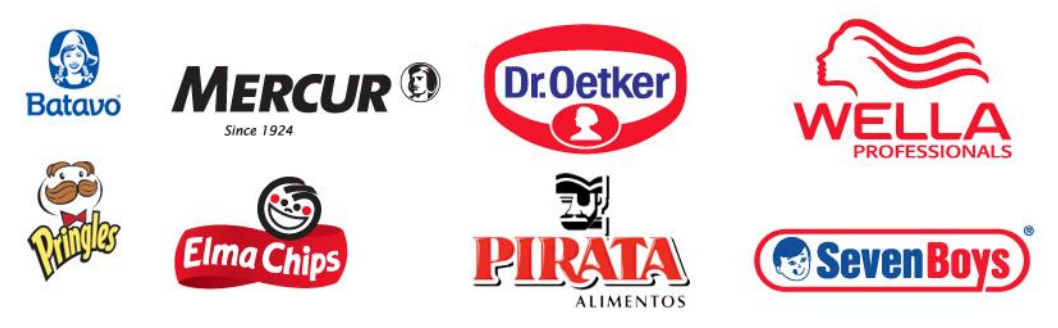

13 Respectivamente: a) Design Innova - Disponível em <http://www.designinnova.blogspot.com.br> acesso em set. 2014.

b) Gina - Disponível em <http://www.gina.com.br> acesso em set. 2014. 
Fig. 11: A adequação do retrato nas marcas do século $X X$ e $X I$. Fonte: Adaptado Batavo; Pringles; Mercur; Elma Chips; Dr. Oetker; Pirata; Wella; Seven Boys. ${ }^{14}$

No sentido contrário às marcas citadas anteriormente, na figura 11 encontramos retratos marcários inspirados em figuras anônimas. Batavo, uma marca voltada para a produção de laticínios, traz a imagem de uma camponesa nos remetendo ao campo; Mercur, empresa produtora de artigos de borracha, recorrerá à imagem literal do Deus romano Mercúrio; Dr. Oetker, voltada para a indústria alimentícia, se expressará através da silhueta, um estilo de retrato muito comum no século XVIII; Wella, afamada marca da indústria cosmética, nos retomará o retrato de perfil, um estilo típico ao Renascimento quando os retratos individuais, em perfil, eram símbolo de notoriedade e poder. Uma atenção especial deve ser dada às marcas Pringles, Elma Hips, Pirata e Seven Boys, voltadas para a indústria alimentícia: todas elas se utilizam da representação da cabeça isolada em suas composições visuais. O que nos chama a atenção é exatamente essa cultura do "isolamento da cabeça humana" como uma recorrência em diversas marcas. De fato, a questão central que nos colocamos seria: Em que sentido tais cabeças isoladas se tornaram tão facilmente suportadas, visualmente falando, a ponto de

14 Respectivamente: a) Batavo - Disponível em <http://www.batavo.com.br> acesso em out. 2014; b) Pringles Disponível em <http://www.mundopringles.com.br> acesso em out. 2014; c) Mercur - Disponível em <http://www.mercur.com.br> acesso em out. 2014; d) Elma Chips - Disponível em <http://www.pepsico.com.br> acesso em out. 2014; e) Dr. Oetker Disponível em <http://www.oetker.com.br> acesso em out. 2014; f) Pirata - Disponível em <http://www.vilma.com.br/produtos/temperocaseiro-pirata/> acesso em out. 2014; g) Wella - Disponível em <http://www.wella.com> acesso em out. 2014; h) Seven Boys Disponível em <http://www.sevenboys.com> acesso em out. 2014. 
tornarem-se retratos de marcas? Porque não estranhamos esta exata situação de uma cabeça "flutuando" junto ao comércio de artefatos?

\section{A cabeça, o dispositivo e alguns "apagamentos"}

No início da nossa discussão recorremos ao Véu de Verônica para evidenciarmos um possível primórdio deste "encanto pela cabeça humana". A cabeça portanto, vem desde a antiguidade se consolidando e sendo readequada às diversas linguagens $e$ necessidades da história da humanidade. A eleição deste "objeto-cabeça" como um possível fenômeno tipicamente humano, nos retoma a fala de Agamben (2009), quando este descreve o que é o dispositivo:

Qualquer coisa que tenha a capacidade de capturar, orientar, determinar, interceptar, modelar, controlar e assegurar os gestos, as condutas, as opiniões e os discursos dos seres viventes. (Agamben, 2009: 40)

Se raciocinarmos o vínculo existente entre a representação da cabeça humana e a estruturação da linguagem do retrato ao longo da história, podemos apontar a cabeça como um método essencial ao funcionamento do dispositivo estabelecido na exata relação entre estas duas esferas: o retrato e a cabeça. Seja em uma máscara mortuária, ou em um artefato industrial contemporâneo, este "símbolo abreviador" possibilita um "tornar visível" deste método em que a representação de uma cabeça nos remete à linguagem do retrato.

À cadeia de enunciados possibilitada por este dispositivo, encontraremos também um certo apagamento dos diversos rastros dispensados ao longo deste fenômeno. Quando Cardoso (2012) nos propõem a definição de um "repertório discursivo", dentro da perspectiva do campo visual dos artefatos, nos deparamos com a descrição de imagens que geram outras imagens, formando cadeias de enunciados que se perpetuam quase sem se reportarem mais, de modo direto, ao artefato que deu origem ao processo. Nesse sentido, o "apagamento", ou até mesmo, um desconhecimento do 
repertório discursivo acerca do "objeto-cabeça", seria uma primeira pista para compreendermos como tornou-se suportável ao ser humano, reagir naturalmente frente à imagem de uma cabeça humana isolada de seu corpo.

Cabe portanto, considerarmos este uso da representação da cabeça isolada junto aos artefatos industrializados. Se simplificarmos este indício visual como uma estratégia que busca associar a personificação das marcas com a aceitação e a aproximação dos consumidores em relação aos produtos, não daremos conta de compreender a profundidade histórica e a herança por trás deste "símbolo abreviador", perpetuado no formato do retrato da marca.

É de importância considerarmos estes vestígios visuais recorrentes em diversos artefatos (figura 11), como um dos múltiplos rastros já delineados por este dispositivo em questão. O retrato da marca contribui na perpetuação de uma cultura humana que se estabeleceu a mais de 4 mil anos atrás. Não será simples desvendarmos 0 porque destas marcas recorrerem à fórmula do retrato na tentativa de estabelecerem uma iconografia própria. É possível desconfiarmos no entanto, desta insistência na representação da cabeça humana como um constante dilema, feito imagem, digno deste ser chamado Humano (figura 12):

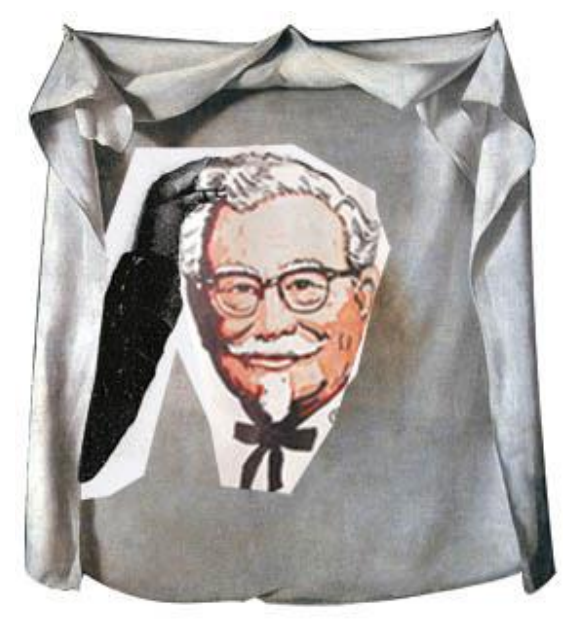

Fig. 12: A cabeça feito um dilema humano. Fonte: Dados da pesquisa, 2014. 
Referências

Agamben, G. (2007). Profanações. São Paulo: Boitempo. (2009). O que é contemporâneo? e outros ensaios.

Santa Catarina: Argos Editora.

Arasse, D. (1989). A guilhotina e o imaginário do terror. São Paulo: Ática.

Aymar, G. C. (1967). The art of portrait Painting: portrait through the centuries as seen through the eyes of a practicing portrait painter. Philadelphia: Chilton Book Company.

Beccati, G. (1965). A escultura grega. Lisboa: Arcadia.

Calderon, A. (1971). Dibujando el retrato. Barcelona: CEAC.

Costa, J. (2008). A imagem da marca: um fenômeno social. São Paulo: Rosari.

Costilhes, A. J. (1985). O que é numismática. São Paulo: Brasiliense.

Courtine, J., \& CORBIN, A., \& VIGARELLO, G. (2008). História do corpo: As mutações do olhar: século XX. Rio de Janeiro: Vozes. v. 3.

Da Vinci, L. (1954). Tratado de la pintura. Buenos Aires: Editorial Losada.

Hogarth, B. (1965) O desenho da cabeça humana sem dificuldade. New York: Evergreen.

Masciotta, M. (1955). Portrait d'artist par eux-mêmes: XIVe-XXe. Milano.

Rancière, J. (2003). Le destin des images. Paris: La Fabrique Éditions.

\section{Websites}

Batavo's trademark. (2014, Oct 13). From: http://www.batavo.com.br/ Carmencita's trademark information. (2014, Oct 13). From: http://www.carmencita.com

Colonel Sanders' images. (2014, Sept 27). From: http://www.hi-andlow.typepad.com

Dr Oetker's trademark (2014, Oct 13). From: http://www.oetker.com.br/ 
Elma Chips' trademark. (2014, Oct 13). From: http://www.pepsico.com.br/

Gina's advertising. (2014, Set 30). From: http://www.designinnova.blogspot.com.br

Gomes da Costa's trademark. (2014, Sept 29). From: http://www.gomesdacosta.com.br

KFC's 2014 trademark. (2014, Sept 27). From: http://www.kfc.com Mercur's trademark. (2014, Oct 13). From: http://www.mercur.com.br/ Mummy mask of a woman. (2014, Sept 22). From: http://www.louvre.fr/

Pirata's trademark. (2014, Oct 13). From: http://www.vilma.com.br/grupo-vilma/marcas/pirata/

Pringles' trademark. (2014, Oct 13). From: http://www.mundopringles.com.br/

Seven Boys' trademark. (2014, Oct 13). From: http://www.sevenboys.com.br/

Uncle Ben's package's and trademark. (2014, Sept 29). From: http://www.unclebens.com

Web gallery of art. (2014, Sept 22). From: http://www.wga.hu/ Wella's trademark. (2014, Oct 13). From: http://www.wella.com 